\title{
Socioendocrine and morphological correlates of paternity in rhesus macaques (Macaca mulatta)
}

\author{
F. B. Bercovitch ${ }^{1,2}$ and P. Nürnberg ${ }^{3}$ \\ ${ }^{1}$ Caribbean Primate Research Center, University of Puerto Rico - Medical Sciences Campus, \\ PO Box 1053, Sabana Seca, PR 00952, USA; ${ }^{2}$ Wisconsin Regional Primate Research Center, \\ University of Wisconsin, Madison, WI 53715, USA; and ${ }^{3}$ Universitatsklinkum Charité, Medizinische \\ Fakultat der Humboldt Universitat zu Berlin, Institut fur Medizinische Genetik, Berlin, Germany
}

\begin{abstract}
When females mate with several males, problems arise in identifying sire and in determining factors contributing to differential male reproductive success. Three potential primary correlates of differential reproduction in males include fighting ability, sperm competition, and body condition. We collected a variety of socioendocrine and morphological measurements from sexually mature rhesus macaques to determine corollaries of paternity. We studied a troop of about 150 rhesus macaques living in a 0.3 ha corral and identified the sires of $70 \%$ of infants using multilocus DNA fingerprints. Eight of 21 males sired offspring, and dominant males were more successful than subordinate males. Neither canine size nor age influenced the probability of siring offspring. Male reproductive success was primarily an outcome of the number of females mated with, which was associated with an ensemble of traits including high dominance rank, large body size, relatively voluminous testicles and good body condition. Testes size was significantly larger in sires than in non-sires, but among sires the number of progeny produced was not correlated with testicle size. Sires began the mating season with more body fat than non-sires, but the energetic costs of mating resulted in a $50 \%$ reduction in abdominal skinfold thickness during the mating season. We conclude that social status exerts a major impact on paternity by affecting the number of females mated with, that male quality is a critical factor modulating paternity, and that male feeding strategies have a direct influence on variation in male reproductive success.
\end{abstract}

\section{Introduction}

Rhesus macaques reside in multimale-multifemale social systems characterized by a restricted mating season, within which females usually mate with multiple males (Carpenter, 1942a; Lindburg, 1971; Manson, 1992). Sire identification is uncertain, and behavioural estimates of paternity in rhesus macaques have consistently generated unreliable inferences regarding true sire (Curie-Cohen et al., 1983; Stern and Smith, 1984; Berard et al., 1994). Dominance rank cannot accurately gauge male reproductive success among rhesus macaques because the relationship between male rank and mating success is only sometimes significant (see Berard et al., 1994; Smith, 1994), and the use of genetic data in establishing paternity has revealed discrepant results with respect to whether high rank confers a reproductive advantage among males (Duvall et al., 1976; Berard et al., 1994; Smith, 1994). Higher ranking adolescent males have larger testicles than lower ranking conspecifics, and undergo accelerated reproductive maturation, but whether these rankrelated patterns of development translate into differences in progeny production is unknown (Bercovitch, 1993). Our study

Received 20 October 1995 scrutinizes potential determinants of male reproductive success using DNA fingerprinting (Jeffreys et al., 1985a, b) to identify sires.

The socioendocrine and morphological correlates of paternity in rhesus macaques include a variety of possible factors, such as dominance rank, testosterone concentrations, testis size, body mass, and physical condition. Testosterone facilitates sexual and aggressive behaviour, rather than dictating its frequency, and the relationship between dominance rank and testosterone concentration is non-uniform across studies and conditions (Bercovitch and Goy, 1990). Furthermore, suppressed testosterone concentrations are not necessarily associated with reduced spermatogenesis or reproductive success (Bercovitch and Goy, 1990). The potential endocrine correlates of differential reproductive success among males have not been ascertained.

The testis size of rhesus macaques is quite substantial compared with that of other primates, indicating the likelihood of intense sperm competition (Bercovitch, 1992a; Dunbar and Cowlishaw, 1992). Sperm production rates are correlated with testes size (Amann, 1970, 1981; Thompson et al., 1979; Johnson et al., 1984) and relatively large testes are characteristic of males residing in multimale mating systems (Harcourt et al., 
1981; Dixson, 1987; Moller, 1988). In addition, copulatory frequencies parallel the potential for sperm competition (Short, 1979; Bercovitch, 1989; Ginsburg and Rubenstein, 1990). As a result of these associations, deposition of large quantities of spermatozoa is presumed to increase the chances of siring offspring, and testes size is expected to correlate with male reproductive success (Popp and DeVore, 1979; Short, 1979, 1981). Despite the widespread acceptance of this contention, no studies have assessed whether male reproductive output is related to testes size within a population.

Testis size is more likely than testosterone concentrations to reflect the potential for sperm competition. Sperm production is proportional to the number of Sertoli cells, and the number of Sertoli cells is the critical biological determinant of testis size (Bardin et al., 1994; Setchell et al., 1994; Sharpe, 1994). Spermatogenetic rates are independent of circulating androgen concentrations (Johnson and Everitt, 1984; Rommerts, 1988) and testicular androgen concentrations are not correlated with number of spermatozoa (Weinbauer and Neischlag, 1990). Gametogenesis and steroidogenesis proceed independently from testicular sources, but whether large testes provide males with a reproductive advantage, by virtue of sperm competition, or facilitate access to females, by augmenting testosterone production, is not known.

A frequent finding is that large body size is a key determinant of male reproductive success in polygynous species (Clutton-Brock et al., 1988; LeBoeuf and Reiter, 1988), yet heavier male savanna baboons, Papio cynocephalus, do not have a reproductive advantage compared with lighter males (Bercovitch, 1989). The effect of body size on male reproductive success in rhesus monkeys has not been investigated. Male body mass varies on a circannual schedule along with mating season periodicity (Lindburg, 1971; Bernstein et al., 1991; Bercovitch, 1992b), and Bercovitch (1992b) suggested that undergoing a 'fatted male phenomenon' is a reproductive tactic that enables males to forgo feeding during the mating season as they spend time and energy in reproductive activities. Males in better condition may be able to increase their reproductive success, but the influence of male condition, or quality, on paternity has not yet been investigated.

Our primary goal was to evaluate how variation in multiple characteristics is reflected in differential offspring production by male rhesus macaques. Three interrelated issues were investigated: (1) what traits distinguish sires from non-sires? (2) what is the relative contribution of various social, endocrine and morphological factors to differential reproductive success? and (3) among reproductively successful males, were specific traits linked with the actual number of progeny produced?

\section{Materials and Methods}

\section{The study population}

We studied a troop of about 150 rhesus macaques living in a 0.3 ha outdoor enclosure at the Sabana Seca Field Station, Puerto Rico ( $18^{\circ} 27^{\prime} \mathrm{N}, 66^{\circ} 12^{\prime} \mathrm{W}$; Bercovitch and Lebrón, 1991). Monkeys were fed commercial monkey chow and they foraged on the grass within the enclosure. Diet was supplemented with fresh fruit and water was available ad libitum. The troop contained 21 potential sires and 47 sexually mature females at the start of the 1990 mating season. Birth dates were known for all subjects, with potential sires ranging in age from 4 to 14 years old. Although 3.25-3.5-year-old rhesus macaque males have impregnated females under restrictive captive conditions (van Wagenen and Catchpole, 1956; Erwin and Mitchell, 1975), the youngest males reported to have sired offspring in group-living situations were 4 years old (Smith and Smith, 1988; Bercovitch and Goy, 1990). A body mass of $5 \mathrm{~kg}$ seems to be a prerequisite for spermatogenesis (Nadler et al., 1993), with males achieving this body mass between 3 and 4 years of age (Rawlins et al., 1984; Saxton and Lotz, 1990).

\section{Data collection}

Males were isolated from the troop at least four times per year for collection of morphological data and blood samples (Bercovitch, 1992b, 1993). All monkeys were anaesthetized with an intramuscular injection of approximately $10 \mathrm{mg}$ ketamine $\mathrm{HCl} \mathrm{kg}{ }^{-\mathrm{I}}$ (Ketaset ${ }^{\mathrm{R}}$; Aveco, Fort Dodge, IA) and morphometric measurements and blood samples were usually collected before 10:30 h from the subjects in a random order. After immobilization, body masses were obtained using a battery-operated scale accurate to the nearest $0.01 \mathrm{~kg}$. Crownrump lengths were measured to the nearest $0.1 \mathrm{~cm}$ with the monkey in left lateral recumbency. Canine size and length and width of each testis were measured using a sliding caliper accurate to $1.0 \mathrm{~mm}$. Maxillary canine measurements were obtained from the gingival margin to the tip of the tooth. Before taking testis measurements, the scrotal sac was stretched to exclude the epididymis from measurement. Abdominal skinfold measurements, called 'fat', were taken $2.5 \mathrm{~cm}$ below the umbilicus using a Lange caliper accurate to the nearest $1.0 \mathrm{~mm}$. Abdominal skinfold in rhesus macaques is significantly correlated with the amount of body fat (Kemnitz and Francken, 1986).

Testicular volume was calculated using the formula for a regular ellipsoid applied to both testes (Bercovitch, 1989, 1993). Testicle size exhibits seasonal periodicity in rhesus macaques and attains a zenith prior to, or at the start of, the mating season (Sade, 1964). During the 1990 mating season, the first copulation was recorded on 7 November, and morphological data collected in October were used in the analyses. Energy costs of mating were defined as differences in body condition from the period just before the onset of the mating season (October) to the period close to the termination of the mating season (January), and body condition was assumed to be reflected in relative amounts of fat. Energy costs were calculated as the January fat amounts as a percentage of October fat amounts. Because one non-sire male died before the January sample was obtained, the analyses of energy costs have a sample size of one less than the other analyses.

Behavioural observations were collected using ad libitum sampling methods (Altmann, 1974) while walking throughout the enclosure. Observers maintained a reasonable distance from subjects to avoid disturbing ongoing activity. Excluding weekends and days devoted to obtaining blood samples and morphometric measurements, social behaviour was recorded on $67 \%$ of days between the first and last observed copulation of 
the season, or an average of 3.5 days per week. Each observation session lasted 3-4 h and began between 08:00 and 09:00 h. Our sampling technique precludes determining copulatory rates, so mating success was defined as the number of different females mated with.

Males who copulated within \pm 12 days of the estimated date of conception, based upon backdating from birth date, were defined as the probable behavioural sires. Determining probable sire based on backdating from birth date is problematic, but Martin (1992) has calculated that the $99 \%$ confidence limits for the duration of gestation in cercopithecines, such as rhesus macaques, is about \pm 10 days. Nine different studies involving over 1200 pregnancies have revealed that duration of gestation in rhesus macaques varies from 130 days to 200 days, but all studies concur in pinpointing a mean duration of 165-170 days (see Roonwal and Mohnot, 1977; Silk et al., 1993). We assumed a gestation duration of 167 days for purposes of identifying probable sires.

Males were arranged into a linear dominance hierarchy based upon the outcome of dyadic agonistic encounters, with only $2.5 \%(n=326)$ of interactions yielding reversals between males. Agonistic behaviours included threats, chases, fights, fear grimaces, avoidance of approaches and supplants over resources.

\section{Testosterone radioimmunoassays}

Analysis of hormone concentration was undertaken at the Wisconsin Regional Primate Research Center using procedures described in detail by Robinson et al. (1975). Samples were assayed in duplicate, with the lower limit of detection $4.84 \mathrm{pg} \mathrm{ml}^{-1}$. The intra- and interassay coefficients of variation were 2.2 and $6.8 \%$, respectively, for the high rhesus macaque male pool, and 3.9 and $7.9 \%$, respectively, for the low pool.

\section{Paternity determination}

Paternity was assigned using likelihood formulae for multilocus profiles (Krawczak and Bockel, 1992) based upon DNA fingerprints obtained with single repetitive oligonucleotide probes, as described in detail elsewhere (Epplen, 1992; Krawczak et al., 1993; Nürnberg et al., 1993). About $6 \mu \mathrm{g}$ Hinf I-digested DNA, obtained from the blood of the relevant animals, and a human standard individual were subjected to electrophoresis on $0.7 \%$ agarose gels, fixed by drying, and probed sequentially with three ${ }^{32} \mathrm{P}$-labelled oligonucleotides: $(\mathrm{GATA})_{4},(\mathrm{CA})_{8}$, and (GTG) 5 to assign the genetic paternity of each offspring. Labelling of probes was performed by polynucleotide kinase reaction (Promega, Madison, WI) using gamma- $\left[{ }^{32} \mathrm{P}\right]$ adenosin- $5^{\prime}$-triphosphate with the highest specific activity available $\left(6000 \mathrm{Ci} \mathrm{mmol}^{-1}\right.$; DuPont NEN, Herts). DNA samples derived from mothers and offspring were placed in adjacent lanes to minimize drift effects that might interfere with identification of non-maternal bands in the offspring. Preliminary identification of possible sires was achieved by matching non-maternal bands with male DNA fingerprint profiles that had been generated on different gels. Finally, true sires were determined by reanalysing the relevant samples on a new gel with potential sires loaded adjacent to the mother-infant dyads. Paternity was assigned on the basis of likelihood ratios of the DNA profiles; those exceeding $10^{10}$ were taken as indicating sirehood. All trios (mother-infantsire) established by multilocus DNA fingerprinting were confirmed using PCR at five single highly polymorphic microsatellite loci (Kayser et al., 1995, 1996), thus providing additional independent verification of paternity assignment.

\section{Statistical analysis}

Nonparametric statistics, including Spearman's rank order correlation coefficient and Kruskal-Wallis ANOVA, were used for determining the effect of dominance rank on multiple variables, whereas parametric statistical tests, such as Pearson's product moment correlation coefficient, $t$ tests and ANOVA were used for pairwise comparisons and associations between non-nominal variables. Analysis of covariance was used to establish whether group differences remained when specific variables were taken into account. Dominance effects were analysed both by dividing the male hierarchy into three equal subcomponents and by using their nominal rank position. By convention, the alpha male was assigned a rank of one, so dominance-related phenomenon would be reflected in significant negative correlations. After multiple pairwise comparisons to eliminate less influential factors were made, multiple regression analysis was performed to evaluate the relative importance of the key components affecting sirehood. Analyses were conducted using SYSTAT 4.0 (Wilkinson, 1990), following standard statistical procedures (Zar, 1974; Sokal and Rohlf, 1981), with the level of significance set at $P<0.05$.

\section{Results}

\section{Comparison of sires with non-sires}

Of the 34 infants born during the 1991 birth season, eight were excluded from analyses because either they or their mother died before we could obtain blood samples for paternity determination, but we were able to establish unambiguously the sire of the remaining 26 infants (Fig. 1). Eight of the 21 males were identified as sires. Sires were characterized by an ensemble of traits that distinguished them from non-sires (Table 1). The two subsets of males differed in all traits examined except for canine size and age. The largest difference was in mating success. Non-sires mated with an average of only $10 \%$ of the number of females that sires mated with. The smallest difference was in crown-rump length, with non-sires averaging $96 \%$ the length of sires.

The greatest statistical difference between the two sets of males was in testes volume. The significant size differential between sire and non-sire testicles was maintained even when those who produced only one offspring were compared with those who produced no offspring $(t=5.275, \mathrm{df}=15$, $P<0.001)$. The minimum combined testes volume of sires $\left(16.22 \mathrm{~cm}^{3}\right)$ was greater than the maximum combined testes volume $\left(15.47 \mathrm{~cm}^{3}\right)$ of non-sires. A testes volume of $16 \mathrm{~cm}^{3}$ converts into an approximate weight of $30.3 \mathrm{~g}$ $(y=1.534 x+5.736$; see Bercovitch and Rodriguez, 1993), and a body mass of $6.1 \mathrm{~kg}$ (testes mass $=0.5 \%$ body mass; see 


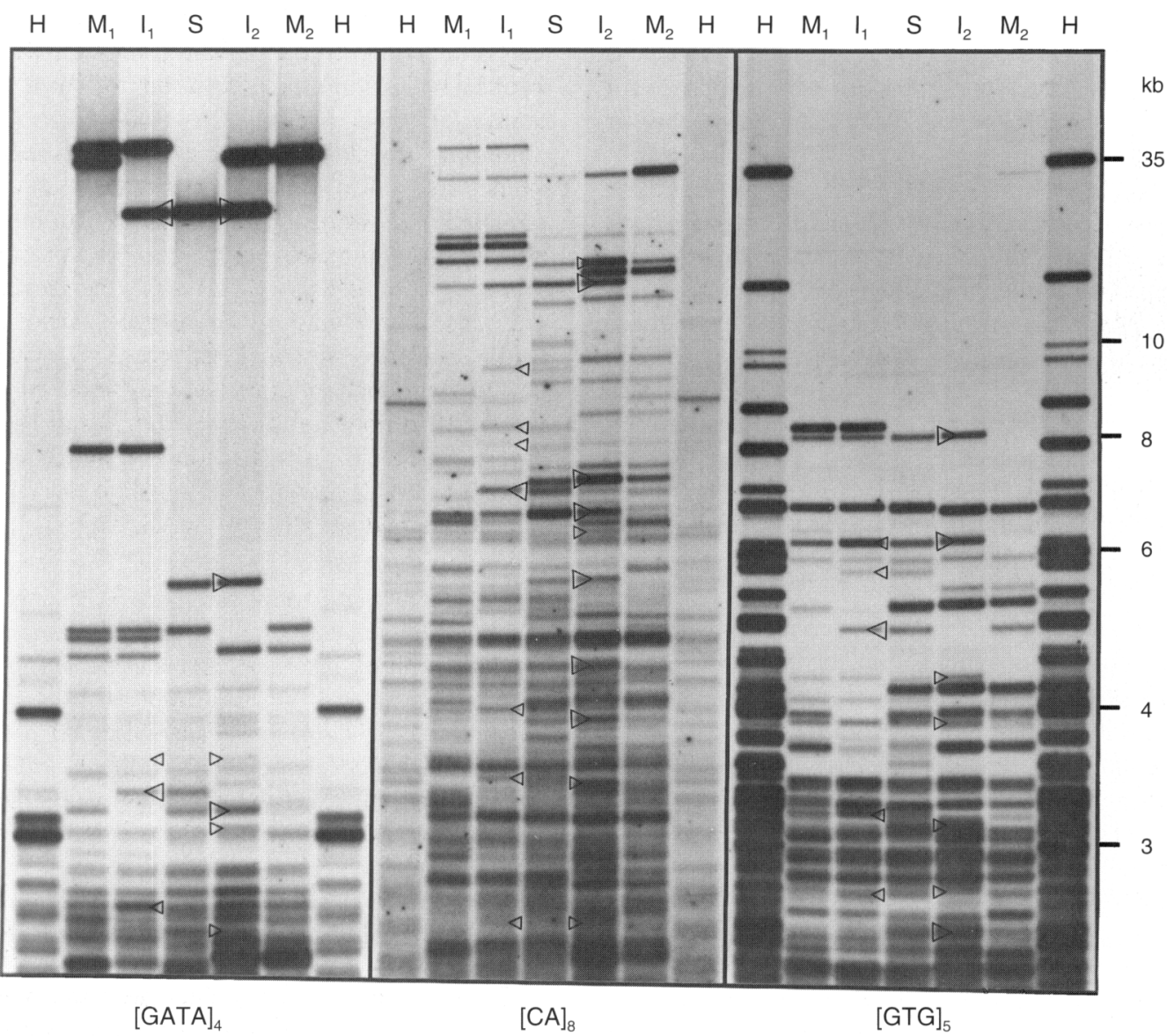

Fig. 1. Example of paternity assignment in rhesus macaques based upon multilocus DNA fingerprints generated with oligonucleotide probes $(\mathrm{GATA})_{4},(\mathrm{CA})_{8}$, and $(\mathrm{GTG})_{5}$. One male $(\mathrm{S})$ sired two infants $\left(\mathrm{I}_{1}, \mathrm{I}_{2}\right)$ born to mothers $M_{1}$ and $M_{2}$, respectively. Human DNA $(H)$ is used as a size marker allowing for better quality control with profiles on other gels. Note the differences in band distribution between the rhesus monkey and the human sample for probes $(\mathrm{GATA})_{4}$ and $(\mathrm{CA})_{8}$, making them more useful for rhesus monkey paternity testing than expected from the human profiles.

Table 1. Differences in socioendocrine and morphological traits of sire and non-sire rhesus macaques

\begin{tabular}{|c|c|c|c|c|}
\hline Variable & $\begin{array}{c}\text { Sire } \\
(n=8)\end{array}$ & $\begin{array}{c}\text { Non-Sire } \\
(n=13)\end{array}$ & $t$ & $P$ \\
\hline Dominance rank & $5.4 \pm 3.9$ & $14.5 \pm 4.6$ & $7.0^{*}$ & 0.001 \\
\hline Age (years) & $6.5 \pm 3.4$ & $4.5 \pm 0.6$ & 2.138 & 0.05 \\
\hline Mating success (number of females) & $5.1 \pm 3.8$ & $0.5 \pm 0.9$ & 4.240 & $<0.001$ \\
\hline Body mass $(\mathrm{kg})$ & $9.1 \pm 1.4$ & $6.9 \pm 1.0$ & 4.191 & $<0.001$ \\
\hline Crown-rump length $(\mathrm{cm})$ & $53.8 \pm 2.7$ & $51.6 \pm 1.8$ & 2.293 & $<0.05$ \\
\hline Canine size $(\mathrm{mm})$ & $2.1 \pm 1.3$ & $1.3 \pm 0.8$ & 1.696 & $>0.10$ \\
\hline Testicular volume $\left(\mathrm{cm}^{3}\right)$ & $28.5 \pm 6.9$ & $9.5 \pm 3.9$ & 8.031 & $<0.001$ \\
\hline Abdominal skinfold (mm) & $7.8 \pm 2.5$ & $3.7 \pm 1.7$ & 4.449 & $<0.001$ \\
\hline Testosterone (ng ml ${ }^{-1}$ ) & $4.0 \pm 1.9$ & $1.9 \pm 1.4$ & 2.987 & $<0.01$ \\
\hline
\end{tabular}

Values reported are the means $+\mathrm{SD}$ recorded at the commencement of the mating season, with variables defined in the text. *Mann-Whitney U statistic.

Bercovitch, 1992a). The minimum body mass of an identified sire was $7.0 \mathrm{~kg}$, but not all males above this threshold sired progeny. When the weight differential between groups was taken into account, sires still had significantly larger testicles than did non-sires (ANCOVA: $F(1,18)=26.225, P<0.001$, multiple $r=0.946$ ).

The male with the largest testicles sired only one offspring and two high ranking 4-year-old males produced progeny. 


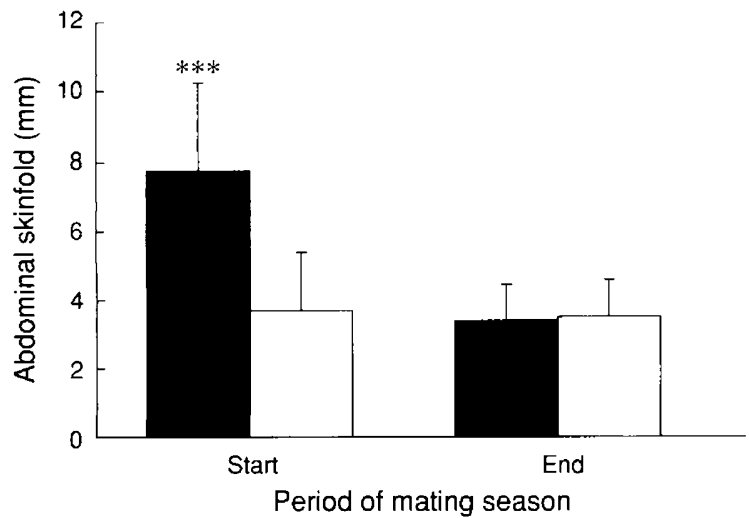

Fig. 2. Comparison of the relative energetic costs sustained by rhesus macaques during the mating season by sires $(\boldsymbol{\square})$ and non-sires $(\square)$. Energy costs were measured indirectly by determining abdominal skinfold thickness. Histogram bars show the mean $\pm \mathrm{SD}$ deviation. $* * * p<0.001$.

Individual testes size significantly increases between 4 and 6 years of age (paired $t=5.556, \mathrm{df}=6, P=0.001$ ), but is stable between 6 and 7 years of age (paired $t=0.647, \mathrm{df}=3$, $p>0.50$ ). Cross-sectional analysis of males $\geq 6$ years of age indicated that testes volume was not dependent upon age $\left(r_{\mathrm{s}}=0.316, n=12, P>0.20\right)$. If variation in testes size is correlated with differences in fitness, and lifetime reproductive success is a reasonable approximation to fitness, then one would expect that the testes size of a male would increase during his lifetime with probable increases in reproductive output. Among the six sires resident in October 1990 who were still in the troop in October 1994, testes size did not increase with probable increases in reproductive output (Sign test: $n=6, x=2, p>0.50$ ) and testes volume was unchanged between the 1990 and 1994 mating seasons (paired $t=0.427$, $\mathrm{df}=5, P>0.50$ ).

Patterns of fat deposition and energy costs exhibited a striking difference between sires and non-sires (Fig. 2). Relative body condition of non-sires was unchanged between the start and end of the mating season (paired $t=-0.340, \mathrm{df}=11$, $P>0.50$ ), while amounts of sire fat fell by $50 \%$ during the mating season (paired $t=-4.034, \mathrm{df}=7, P<0.01$ ). By the end of the mating season, body condition was indistinguishable between sires and non-sires $(t=-0.254, \mathrm{df}=18, P>0.50)$. While sires lost $5 \%$ of their body mass during the mating season (paired $t=-2.417, \mathrm{df}=7, P=0.046$ ), non-sires gained $5 \%$ in body mass (paired $t=1.544, \mathrm{df}=11, P>0.10$ ). Despite these opposite trajectories in body mass changes, sires still weighed significantly more than non-sires at the end of the mating season $(8.56 \pm 0.97$ versus $7.19 \pm 0.70 \mathrm{~kg} ; t=3.681$, $\mathrm{df}=18, P<0.01)$. The small change in body mass of sires coupled with the large decrement in body fat suggests that an energetic cost of mating is met by utilizing fat reserves.

Although sires differed from non-sires in many characteristics, establishing the sire of a particular infant based upon mating activity was not possible. Thirteen females were observed mating with only a single partner within \pm 12 days of the estimated date of conception. The mating partner matched the actual sire in only half of the cases $(n=7)$. If the number of days between consecutive births of infants within a season was identical to the number of days between consecutive conceptions by the infants' mothers, then the minimum interval between siring two offspring by a single male was I day.

In summary, although younger males tended to have smaller testes than older males, age was not associated with the probability of siring offspring among sexually mature males because young males occupied high ranking positions and dominance status was linked with sirehood. Testicular volume ascended to an asymptote at about 6 years of age, and did not continue to increase commensurate with probable increases in offspring production. Sires were in better condition and were heavier than non-sires at the beginning of the mating season, but the energetic costs of mating resulted in comparable body conditions by the end of the mating season. Differences in canine size had no effect on variability in male reproductive success.

\section{Factors associated with differences in male reproductive success}

Dominance rank features prominently in discussions of determinants of male reproductive success, and was associated with probability of siring offspring in our population. Two offspring were sired by middle ranking males, while the remaining $92 \%$ of infants were sired by males in the top third of the hierarchy. The alpha male in the troop sired $27 \%$ of progeny, but the largest number of infants produced was associated with a high ranking adolescent male.

Of the nine variables tested, only the number of females mated with was significantly correlated with the number of progeny produced among the seven highest ranking males in the troop $(r=0.827, P<0.05)$, with their relative position in the upper echelons of the troop tending to affect their reproductive output (rank $\times$ offspring: $r_{\mathrm{s}}=-0.761, P=0.07$ ). The number of females mated with was not associated with testicular volume among the high ranking males $(r=0.446$, $P>0.20$ ), nor was reproductive output reflected in relative testes size $(r=0.254, P>0.50)$.

An overview of rank effects was established by partitioning the 21 males into three dominance categories of equal size. Dominance status was independent of age $(F(2,18)=2.634$, $P=0.10$ ), but high ranking males were heavier $(F(2,18)=12.845, \quad P<0.001)$ and fatter $(F(2,18)=9.305$, $P<0.01)$ than middle or low ranking males. Dominant males had significantly larger testes $(\mathrm{F}(2,18)=13.461, P<0.001)$, and testosterone concentrations followed a similar, but not statistically significant, pattern $(F(2,18)=1.87, P>0.10)$. Rank differences in testes size disappeared when weight was factored into the analysis as a covariate (ANCOVA: $\mathrm{F}(2,17)=2.485$, $P>0.10$ ).

In summary, dominant males had a reproductive advantage over subordinate males, but offspring production among males in the upper echelon was dependent upon their mating success rather than their physiological and morphological attributes. Differences in reproductive output among the highest ranking males were not associated with variation in age, body mass, testes size, body condition or testosterone concentrations, but the more females a high ranking male mated with, the more offspring he sired. 
Table 2. Correlation matrix of socioendocrine and morphological characters contributing to differential reproductive success among male rhesus macaques

\begin{tabular}{lccccccc}
\hline & Infants & Rank & Females & Weight & Testes & Fat & $T$ \\
\hline Infants & - & $-\mathbf{0 . 7 7 2 * * *}$ & $\mathbf{0 . 8 5 2 ^ { * * * }}$ & $\mathbf{0 . 4 9 3 ^ { * }}$ & $\mathbf{0 . 5 7 7 ^ { * * }}$ & $\mathbf{0 . 4 3 8 ^ { * }}$ & $\mathbf{0 . 1 9 1}$ \\
Rank & $-\mathbf{0 . 7 2 6}$ & - & $-0.844^{* * *}$ & $-0.516^{*}$ & $-0.673^{* *}$ & $-0.731^{* * *}$ & $-0.501^{*}$ \\
Females & $\mathbf{0 . 7 9 4}$ & $-0.867^{*}$ & - & $0.585^{* *}$ & $0.754^{* * *}$ & $0.603^{* *}$ & 0.229 \\
Weight & $\mathbf{0 . 2 0 0}$ & -0.587 & 0.317 & - & $0.862^{* * *}$ & $0.850^{* * *}$ & $0.566^{* *}$ \\
Testes & $\mathbf{0 . 1 8 8}$ & -0.611 & 0.459 & $0.934^{* * *}$ & - & $0.799^{* * *}$ & $0.554^{* *}$ \\
Fat & $\mathbf{0 . 0 3 8}$ & -0.537 & 0.276 & $0.713^{*}$ & 0.625 & - & $0.560^{* *}$ \\
T & $\mathbf{0 . 2 9 8}$ & 0.084 & -0.545 & 0.114 & 0.008 & 0.008 & - \\
\hline
\end{tabular}

Values in each cell are Pearson's product-moment correlation coefficients, except those reported for rank, which are Spearman's rank-order correlation coefficients. Only those traits found to differ between sires and non-sires were included in the matrix. Infants, number of offspring sired; Females, number of females mated with; $T$, testosterone concentration. Numbers above the diagonal are derived from analyses of all sexually mature males $(n=21)$, while those below the diagonal were obtained from sires only $(n=8)$. The bold row and column highlight the associations between the number of offspring produced and male traits.

$* P<0.05 ; * * P<0.01 ; * * * P<0.001$.

The aggregate of components linked with the probability of siring offspring were highly intercorrelated. Exclusion of those factors that were indistinguishable between sires and non-sires yielded 21 pairwise correlations, of which only two, both involving testosterone, were not statistically significant (Table 2). This tight linkage among traits was much less apparent in the eight sires, where only four statistically significant correlations emerged (see Table 2). In both sets of data, progeny production was correlated with mating success, mating success with dominance rank, body mass with testicular volume, and body mass with abdominal skinfold thickness. When combined with the data on differential reproduction among males in the top third of the hierarchy, the results indicate that the chances of siring offspring were largely a function of dominance rank, mating success, body mass, testes volume and physical condition. The number of progeny produced was a direct outcome of the number of females mated with, and dominance rank accounted for nearly two-thirds of the variance in the number of females mated with.

The investigation of the correlates of paternity was completed by using multiple regression analysis of the key independent variables as a means of determining more precisely how male attributes interacted to affect male reproductive success. The two fundamental dependent variables we sought to explain were number of offspring sired and number of females mated with.

The number of females mated with accounted for $73 \%$ of the variance in progeny production (see Table 2), and multiple regression analysis incorporating body mass, testes volume, and fat amounts had little effect on the coefficient of determination $\left(r^{2}=0.764\right)$. By themselves, body mass, testes volume and fat amounts explained about one-third of the variance in male reproductive success $\left\langle r^{2}=0.335 ; \quad \mathrm{F}(3,17)=2.855\right.$, $P=0.07$ ). Dominance rank largely affected the number of females mated with (Kruskal-Wallis $\mathrm{H}=12.409, P=0.002$ ). Even when weight was taken into account, high ranking males mated with significantly more females than did lower ranking males (ANCOVA: $F(2,17)=5.144, \quad P<0.02$, multiple $r=0.768$ ). Testes volume explained almost $60 \%$ of the variance in mating success $\left(r^{2}=0.569\right)$. Multiple regression analysis

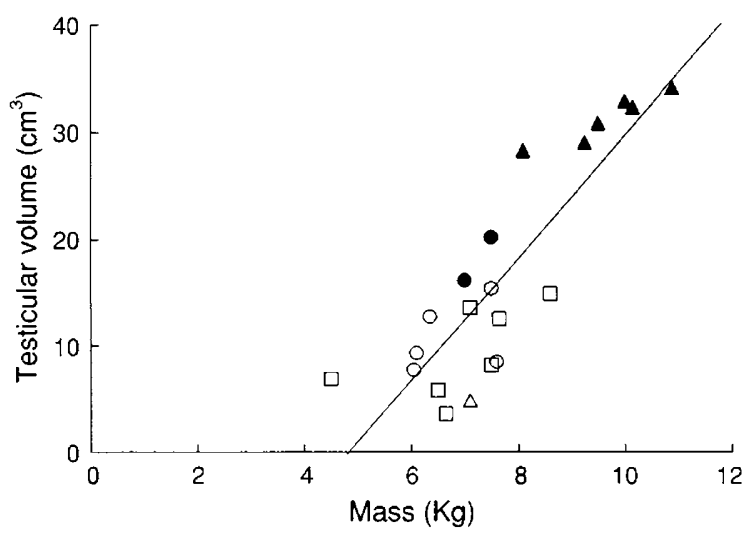

Fig. 3. A scatterplot demonstrating the relationship among testes volume, body mass, dominance rank, and paternal status in rhesus macaques. (^), High rank, sire; $(\wedge)$, high rank, non-sire; $(\bullet)$, middle rank, sire; (o), middle rank, non-sire; $(\square)$, low rank, non-sire; no low ranking males sired offspring. $r=0.862, n=21, P<0.001$.

combining testes volume with body mass and fat amounts did not improve the ability to account for variation in mating success $\left(r^{2}=0.592\right)$. In general, the effect of dominance status was superimposed upon the relationship between testes volume and mass ( $y=5.87 x-28.45 ; r^{2}=0.743$; Fig. 3 ).

In summary, the major determinant of male reproductive success was the number of females mated with, and the key correlate of the number of females mated with was testicular volume. However, testicular volume was a function of body mass. Both social and morphological factors contribute to variation in male reproductive output.

\section{Discussion}

Two cardinal conclusions emerge from our study. First, male reproductive output was a function of male mating success, or the number of females mated with; and second, the key component associated with the number of females mated with was testicular volume, which was linked tightly to dominance 
status, body mass and body condition. The link between differences in male reproductive success and variation in number of mating partners conforms with other studies of macaques (Paul et al., 1993; Berard et al., 1994). Furthermore, the failure to pinpoint accurately a sire based upon mating behaviour around the presumed time of conception is a common finding in research on rhesus macaques (see Berard $e t$ al., 1994). However, a precise test of this presumed disconnection awaits a thorough investigation of mating behaviour that incorporates observations of females throughout the day during their probable conception phase. Of all the morphological traits examined, testes volume was most strongly correlated with progeny production, but, among sires, testes size and actual reproductive success were uncorrelated. Testes volume was largely a function of body mass, and holding body mass constant eliminated the rank differences in testes size. However, even with body mass taken into account, sires had larger testes than did non-sires.

A cluster of traits, including high dominance rank, large body mass, relatively voluminous testicles, good body condition, and mating with many females, characterized sires. Our results provide a perspective on three hypotheses regarding the determinants of male reproductive success: the aggressive male competition hypothesis, the sperm competition hypothesis, and the good quality male hypothesis. These three hypotheses are not necessarily mutually exclusive, but emphasize different primary factors possibly responsible for variation in male reproductive success.

The aggressive male competition hypothesis is centred on the idea that sexual selection promotes size dimorphism in traits such as canine teeth and body mass among polygynous species (Trivers, 1972; Wilson, 1975; Alexander et al., 1979; Plavcan and van Schaik, 1992). Males with greater development of such traits are expected to have a reproductive advantage due to their prowess in physical combat with other males over access to females. Although wounding among male rhesus monkeys is more prevalent during the mating season (Vandenbergh and Vessey, 1968; Wilson and Boelkins, 1970), observers have remarked on the lack of fighting between rhesus macaque males over access to females in oestrus (Conaway and Koford, 1964; Lindburg, 1971). Frequent fighting among primates is often associated with instability of the dominance hierarchy, and a strict, linear dominance structure reduces the probability of escalated confrontations (Bercovitch, 1991). The male dominance hierarchy among our subjects was extremely stable, a condition that tends to undercut the aggressive competition hypothesis. The degree to which aggressive competition contributes to dominance standing was not investigated, but canine size was independent of the probability of siring offspring, and differences in body mass among sires was not associated with variation in reproductive output.

Among rhesus macaques, older males with worn and broken canines, who weigh less than prime age males with pristine canines, could have a greater reproductive output. Heavier males did sire more offspring than did lighter males, suggesting that surpassing a minimum body mass probably enables males to enter the arena of competition for access to females, but male mass differentials do not dictate reproductive differentials. Body mass is correlated with probable reproductive success among male mammals residing in unimale mating systems (for example, see Andersson and Fedak, 1985; Clutton-Brock et al., 1988; LeBoeuf and Reiter, 1988), but not among primate males living in either unimale (Dunbar, 1984) or multimale (Nieuwenhuijsen et al., 1987; Bercovitch, 1989) mating systems. Body size in primates probably influences male reproduction less than do social skills (Bercovitch, 1989, 1991). Therefore, we find little evidence to support the idea that fighting ability, as measured by either canine size or body mass, is a key component affecting differential reproductive success in male rhesus monkeys once males have surpassed a minimum size.

The sperm competition hypothesis assumes that larger testicles provide males with a reproductive advantage, involving nonagonistic competition within the female reproductive tract, which translates into a link between testis size and fitness (for example, see Popp and DeVore, 1979; Short, 1979, 1981). Although variation in testes size contributed to differences in male reproductive success, beyond a testes size threshold the number of offspring sired was not correlated with testes size. Testes size did not increase with age concurrent with probable increases in reproductive output, and 4-year-old male sires, who had not produced offspring in previous years, had testes as large as prime age males, who had produced offspring previously. Both of these patterns contradict a link between fitness and testes size. Furthermore, traits with a high heritability tend to have a minimal impact on fitness (Falconer, 1981; Charlesworth, 1987), and testis size has a high heritability (Schinkel et al., 1984; Toelle and Robison, 1985; Foote, 1989). Therefore, in spite of the connection between sperm production and testis size, and the association between intensity of sperm competition and testis size, both the longitudinal data reported here, and those obtained from heritability studies, indicate that variation in testes size is unlikely to reflect differences in either reproductive success or fitness.

Rhesus macaque copulatory behaviour consists of a series of intromissions, interspersed with dismounts, before ejaculation (Carpenter, 1942a; Lindburg, 1971), and these multiple mount series are more likely to occur among males residing in multimale, than in monogamous or unimale, mating systems (Dixson, 1987). Dominant male rhesus macaques have longer mount series and more copulatory activity than those of subordinates (Carpenter, 1942a; Kaufmann, 1965; Shively et al., 1982), but evidence is not available regarding potential rank effects on the number of intromissions per mount or mounts before ejaculation. Although frequent ejaculation decreases number of spermatozoa per ejaculate (Oldereid et al., 1984; Levin et al., 1986), the sperm output of bucks (MacMillan and Hafs, 1967) and bulls (Almquist, 1973) increases when noncopulatory mounts precede intromission. We suggest that the longer mount series of dominant males is accompanied by a greater number of thrusts per intromission, or mounts before ejaculation, to maximize sperm delivery by increasing sperm output per ejaculate.

Given that male rhesus macaques who mated with more females sired more offspring, and that only a single day separated consecutive conceptions by a male in the current study, our data conflict with the suggestion (Small, 1988) that sperm depletion mediates female reproductive strategies or male reproductive success. Among the rhesus macaques on Cayo Santiago, sires had higher ejaculatory frequencies and mated with a greater number of females than did non-sires 
(Berard et al., 1994). In North India, Lindburg (1971) reported observing a male rhesus macaque ejaculate twice within $6 \mathrm{~min}$. Rhesus macaques masturbate to ejaculation when associating with oestrous females (Carpenter, 1942b), and savanna baboons, Papio cynocephalus, masturbate to ejaculation when in consort with a female (Ransom, 1981; Bercovitch, 1989), patterns of behaviour not likely to evolve if sperm depletion hinders male reproductive success. Paternity analysis using DNA fingerprinting in multimale troops of Barbary macaques, $M$. sylvanus, uncovered a positive correlation between ejaculatory frequency on the probable days of conception and actual reproductive success (Paul et al., 1993), and male savanna baboons increase ejaculatory rates commensurate with the probability of ovulation (Bercovitch, 1989). These studies of nonhuman primates residing in multimale mating systems concur in suggesting that sperm depletion is unlikely to modulate male reproductive success because a greater reproductive output seems to coincide with higher ejaculatory frequencies.

Therefore, we find equivocal evidence supporting the sperm competition hypothesis. For a given body size, males with larger testes sired more offspring, but testes size did not reflect actual male reproductive output among sires and was not likely to be correlated with fitness or lifetime reproductive success. Tight mate guarding, or long-term maintenance of consortships, reduces the chances of opponents mating with a female and probably paces ejaculatory frequency in a fashion that renders sperm depletion inconsequential to male reproductive success.

The good quality male hypothesis is based on the idea that males in good physical condition can withstand the energetic demands that accompany control of access to females during a restricted mating season (for example, Anderson and Fedak, 1985; Andersson, 1994). Males in good condition may be able to partition resources into both survival and reproduction simultaneously, which could result in a reproductive advantage (see Harvey and Bradbury, 1991). A subsidiary component to the quality hypothesis is the idea that the fatted male phenomenon functions as a reproductive tactic that buffers males against the energetic costs of mating by providing them with an energy source during a season when time budgets are altered by reductions in feeding activity and increases in sociosexual activity (Bercovitch, 1992b). In the study reported here dominant males allocated more resources to both growth (body mass, fat) and reproduction (testes volume, mating behaviour) than did their subordinate peers, and such a dual investment was associated with greater production of progeny. Concurrence of traits advantageous to male reproductive success have been documented in species ranging from lyrebirds to red deer (Andersson, 1994).

A key finding of our study was that body condition affected male reproductive output. Sires lost $50 \%$ of their fat during the mating season, indicating a substantial energetic cost, but the effect of this expenditure was buffered because sires were in better condition than non-sires at the start of the mating season. The relative difference in premating season fat amounts between sires and non-sires was greater than the difference in any other morphological trait, except for testes size. Over $90 \%$ of the variance in male body mass in rhesus macaques is due to fat, not lean muscle mass or stature (Kemnitz and Francken,
1986). In summary, good quality males were able to invest both time and energy into mating effort and resources into improved body condition. This evidence supports the idea that good quality males sire more offspring than do poor quality males.

Our research has major implications for the view that females augment their reproductive success by concentrating on access to food, whereas males achieve this goal by channelling resources into access to females (Trivers, 1972; Wilson, 1975; Harvey and Bradbury, 1991; Andersson, 1994). Our data confirmed that mating with more females yielded more offspring, but this outcome was a function of male body condition. If obtaining and maintaining access to females is a consequence of male quality, then male feeding behaviour has a direct, not a secondary, effect on male reproductive success. Feeding strategies among males should be considered an important component of their reproductive strategies (Bercovitch, 1992b). Darwin (1871) reasoned that female body condition at the start of the mating season had a large impact on reproductive success, and our data suggest that this pattern also holds for male rhesus macaques.

In conclusion, the key determinant of male reproductive success was the number of females mated with. The major factors explaining variation in number of females mated with were dominance rank and testes size, and these traits were tightly associated with body mass and physical condition. A complex of characteristics indicative of good quality earmarked sires, and dominant males were more likely to display such traits than were subordinate males. We found little support for the fighting ability hypothesis, some evidence favouring the sperm competition hypothesis, and convincing evidence that male quality is a major determinant of differences in progeny production among rhesus macaques.

The authors thank M. Lebrón for assistance in data collection, J. Berard, M. Bruford, M. Kessler and J. Wickings for their constructive input, and G. Scheffler and D. Wittwer for performing the hormone assays. Funds for research have been awarded by the H. F. Guggenheim Foundation (FBB), the National Science Foundation (IBN 9209510; FBB), the Deutsche Forschungsgemeinschaft (Nu 50/3-1; PN), and the National Institutes of Health (RR03640; CPRC). This is publication No. 36-0I7 of the WRPRC.

\section{References}

Alexander RD, Hoogland JL, Howard RD, Noonan KM and Sherman PW (1979) Sexual dimorphisms and breeding systems in pinnipeds, ungulates, primates, and humans. In Evolutionary Biology and Human Social Behavior; An Anthropological Perspective pp 402-435 Eds NA Chagnon and W Irons. Duxbury Press, North Scituate

Almquist JO (1973) Effects of sexual preparation on sperm output, semen characteristics and sexual activity of beef bulls with a comparison to dairy bulls Journal of Animal Science 36 331-336

Altmann J (1974) Observational study of behaviour: sampling methods Behaviour 49 227-267

Amann RP (1970) Sperm production rates. In The Testis, Vol I pp 433-482 Eds AP Johnson, WR Gomes and NL Vandemark. Academic Press, New York

Amann RP (1981) A critical review of methods for evaluation of spermatogenesis from seminal characteristics Journal of Andrology 2 37-58

Anderson SS and Fedak MA (1985) Grey seal males: energetic and behavioural links between size and sexual success Animal Behaviour 33 829-838 Andersson M (1994) Sexual Selection Princeton University Press, Princeton 
Bardin CW, Cheng CY, Mustow NA and Gunsalus GL (1994) The Sertoli cell. In The Physiology of Reproduction (2nd Edn) pp 1291-1333 Eds E Knobil and ID Neill. Raven Press, New York

Berard JD, Nürnberg P, Epplen JT and Schmidtke J (1994) Alternative reproductive tactics and reproductive success in male rhesus macaques Behaviour 129 $177-201$

Bercovitch FB (1989) Body size, sperm competition, and determinants of reproductive success in male savanna baboons Evolution 43 1507-1521

Bercovitch FB (1991) Social stratification, social strategies, and reproductive success in primates Ethology and Sociobiology 12 315-333

Bercovitch FB (1992a) Sperm competition, reproductive tactics, and paternity in savanna baboons and rhesus macaques. In Paternity in Primates pp 225-237 Eds RD Martin, AF Dixson and EJ Wickings. Karger, Basel

Bercovitch FB (1992b) Estradiol concentrations, fat deposits, and reproductive strategies in male rhesus macaques Hormones and Behavior 26 272-282

Bercovitch FB (1993) Dominance rank and reproductive maturation in male rhesus macaques (Macaca mulatta) journal of Reproduction and Feritity 99 $113-120$

Bercovitch FB and Goy RW (1990) The socioendocrinology of reproductive development and reproductive success in macaques. In Socioendocrinology of Primate Reproduction pp 59-93 Eds TE Ziegler and FB Bercovitch. Wiley-Liss, New York

Bercovitch FB and Lebrón MR (1991) Impact of artificial fissioning and social networks on levels of aggression and affiliation in primates Aggressive Behavior 17 17-25

Bercovitch FB and Rodriguez IF (1993) Testis size, epididymis weight, and sperm competition in rhesus macaques American Journal of Primatology 30 $163-168$

Bernstein IS, Ruehlmann TE, Judge PG, Lindquist $T$ and Weed IL (1991) Testosterone changes during the period of adolescence in male rhesus monkeys (Macaca mulatta) American Journal of Primatology 24 29-38

Carpenter CR (1942a) Sexual behavior of free-ranging rhesus monkeys (Macaca mulatta). I. Specimens, procedures and behavioral characteristics of estrus Journal of Comparative Psychology 33 113-142

Carpenter CR (1942b) Sexual behavior of free-ranging rhesus monkeys (Macaca mulatta). II. Periodicity of estrus, homosexual, autoerotic and non-conformist behavior Journal of Comparative Psychology 33 143-162

Charlesworth B (1987) The heritability of fitness. In Sexual Selection: Testing the Alternatives pp 21-40 Eds JW Bradbury and MB Andersson. John Wiley, New York

Clutton-Brock TH, Albon SD and Guinness FE (1988) Reproductive success in male and female red deer. In Reproductive Success pp. 325-343 Ed TH Clutton-Brock. University of Chicago Press, Chicago

Conaway CH and Koford CB (1964) Estrous cycles and mating behavior in a free-ranging band of rhesus monkeys journal of Mammology 45 577-588

Curie-Cohen M, Yoshihara D, Luttrell L, Benforado K, MacCluer JW and Stone WH (1983) The effects of dominance on mating behavior and paternity in a captive troop of rhesus monkeys American Journal of Primatology 5 127-138

Darwin C (1871) The Descent of Man and Selection in Relation to Sex Murray, London

Dixson AF (1987) Observations on the evolution of the genitalia and copulatory behavior in male primates Journal of Zoology, London $213423-443$

Dunbar RIM (1984) Reproductive Decisions Princeton University Press, Princeton

Dunbar RIM and Cowlishaw G (1992) Mating success in male primates: dominance rank, sperm competition and alternative strategies Animal Behaviour 44 1171-1173

Duvall SW, Bernstein IS and Gordon TP (1976) Paternity and status in a rhesus monkey group Journal of Reproduction and Fertility 47 25-31

Epplen JT (1992) The methodology of multilocus DNA fingerprinting using radioactive or non-radioactive oligonucleotide probes specific for simple repeat motifs. In Advances in Electrophoresis pp 59-114 Eds A Chrambach, MJ Dunn and BJ Radola. VCH Publishers, Weinheim

Erwin J and Mitchell G (1975) Initial heterosexual behavior of adolescent rhesus monkeys (Macaca mulatta) Archives of Sexual Behavior 4 97-104

Falconer DS (1981) Introduction to Quantitative Genetics (2nd Edn) Longman, London

Foote RH (1989) Value of testicular and sperm profiles in optimizing reproductive success: lessons learned from selective breeding programs of domestic and laboratory animals. In Sperm Measures and Reproductive Success pp 107-126 Eds EJ Burger, RG Tardiff, AR Scialli and H Zenick. Alan R Liss, New York
Ginsburg JR and Rubenstein DI (1990) Sperm competition and variation in zebra mating behavior Behavioral Ecology and Sociobiology 26 427-434

Harcourt AH, Harvey PH, Larson SG and Short RV (1981) Testis weight, body weight and breeding system in primates Nature 293 55-57

Harvey PH and Bradbury JW (1991) Sexual selection. In Behavioural Ecology (3rd Edn) pp 203-233 Eds JR Krebs and NB Davies. Blackwell Scientific, Oxford

Jeffreys AJ, Wilson V and Thein SL (1985a) Hypervariable minisatellite regions in human DNA Nature 314 67-73

Jeffreys AJ, Wilson V and Thein SL (1985b) Individual-specific 'fingerprints' of human DNA Nature 31.6 76-79

Johnson L, Petty CS and Neaves WB (1984) Influence of age on sperm production and testicular weights in men Journal of Reproduction and Fertility $70211-218$

Johnson M and Everitt B (1984) Essential Reproduction Blackwell Scientific, Oxford

Kaufman JH (1965) A three-year study of mating behavior in a free-ranging band of rhesus monkeys Ecology 46 500-512

Kayser M, Ritter H, Bercovitch F, Mrug M, Roewer L and Nürnberg P (1995) Increased microsatellite variability in Macaca mulatta compared to humans due to a large scale deletion/insertion event during primate evolution Electrophoresis 16 I607-1611

Kayser M, Ritter H, Bercovitch F, Mrug M, Roewer L and Nürnberg P (1996) Identification of highly polymorphic microsatellites in the rhesus macaque, Macaca mulatta, by cross-species amplification Molecular Ecology 5 157-159

Kemnitz JW and Francken GA (1986) Characteristics of spontaneous obesity in male rhesus monkeys Physiology and Behavior 38 477-483

Krawczak M and Bockel B (1992) A genetic factor model for the statistical analysis of multilocus DNA fingerprints Electrophoresis 13 10-17

Krawczak M, Berard JD, Bercovitch FB, Schmidtke J and Nürnberg P (1993) Power and limits of DNA-profiling in primate populations: paternity assessment in rhesus macaques from Cayo Santiago Primates 34 395-402

La Boeuf BJ and Reiter J (1988) Lifetime reproductive success in northern elephant seals. In Reproductive Success pp 344-362 Ed TH Clutton-Brock. University of Chicago Press, Chicago

Levin RM, Latimore J, Wein AJ and Van Arsdalen KN (1986) Correlation of sperm count with frequency of ejaculation Fertility and Sterility 45 732-734

Lindburg DG (1971) The rhesus monkey in North India. In Primate Behavior pp 1-106 Ed LA Rosenblum. Academic Press, New York

MacMillan KL and Hafs HD (1967) Semen output of rabbits ejaculated after varying sexual preparation Proceedings of the Society for Experimental Biology and Medicine 125 1278-1281

Manson JH (1992) Measuring female mate choice in Cayo Santiago rhesus macaques Animal Behaviour 44 405-416

Martin RD (1992) Female cycles in relation to paternity in primate societies. In Paternity in Primates pp 238-274 Eds RD Martin, AF Dixson and EJ Wickings. Karger, Basel

Moller AP (1988) Ejaculate quality, testes size and sperm competition Journal of Human Evolution 17 479-488

Nadler RD, Manocha AD and McClure HM (1993) Spermatogenesis and hormone levels in rhesus macaques inoculated with simian immunodeficiency virus Journal of Medical Primatology 22 325-329

Nieuwenhuijsen K, de Neef KJ, van der Werff ten Bosch JJ and Slob AK (1987) Testosterone, testis size, seasonality, and behavior in group-living stumtail macaques (Macaca arctoides) Hormones and Behavior 21 153-167

Nürnberg P, Berard JD, Bercovitch F, Epplen JT, Schmidtke J and Krawczak M (1993) Oligonucleotide fingerprinting of free-ranging and captive rhesus macaques from Cayo Santiago: paternity assignment and comparison of heterozygosity. In DNA Fingerprinting: State of the Science pp 445-451 Eds SDJ Pena, AJ Jeffreys, JT Epplen and P Chakraborty. Birkhauser-Verlag, Basel

Oldereid NB, Gordeladze JD, Kirkhus B and Purvis K (1984) Human sperm characteristics during frequent ejaculation Journal of Reproduction and Fertility 71 135-140

Paul A, Kuester J, Timme A and Arnemann J (1993) The association between rank, mating effort, and reproductive success in male Barbary macaques (Macaca sylvanus) Primates 34 491-502

Plavcan JM and van Schaik CP (1992) Intrasexual competition and canine dimorphism in anthropoid primates American Journal of Physical Anthropology $87461-477$

Popp JL and DeVore I (1979) Aggressive competition and social dominance theory: synopsis. In The Great Apes: Perspectives on Human Evolution, Vol 5 pp 317-338 Eds DA Hamburg and ER McCown. Benjamin/Cummings, Menlo Park 
Ransom TW (1981) Beach Troop of the Gombe Bucknell University Press, Lewisburg

Rawlins RG, Kessler MJ and Turnquist JE (1984) Reproductive performance, population dynamics and anthropometrics of the free-ranging Cayo Santiago thesus macaques Journal of Medical Primatology 13 241-259

Robinson JA, Scheffler G, Eisele SG and Goy RW (1975) Effects of age and season on sexual behavior and plasma testosterone and dihydrotestosterone concentrations of laboratory-housed male rhesus monkeys (Macaca mulatta) Biology of Reproduction 13 203-210

Rommerts FFG (1988) How much androgen is required for maintenance of spermatogenesis? Journal of Endocrinology 116 7-9

Roonwal ML and Mohnot SM (1977) Primates of South Asia Harvard University Press, Cambridge

Sade DS (1964) Seasonal cycle in size of testes of free-ranging Macaca mulatta Folia primatologica 2 171-180

Saxton JL and Lotz WG (1990) Growth of rhesus monkeys during the first 54 months of life Journal of Medical Primatology 19 119-136

Schinkel AP, Johnson RK and Kittok RJ (1984) Testicular development and endocrine characteristics of boars selected for either high or low testis size Journal of Animal Science 58 675-685

Setchell BP, Maddoors S and Brooks DE (1994) Anatomy, vasculature, innervation, and fluids of the male reproductive tract. In The Physiology of Reproduction (2nd Edn) pp 1063-1175 Eds E Knobil and JD Neill. Raven Press, New York

Sharpe RM (1994) Regulation of spermatogenesis. In The Physiology of Reproduction (2nd Edn) pp 1363-1434 Eds E Knobil and JD Neill. Raven Press, New York

Shively C, Clarke S, King N, Schapiro S and Mitchell G (1982) Patterns of sexual behavior in male macaques American Journal of Primatology 2 373-384

Short RV (1979) Sexual selection and its component parts, somatic and genital selection as illustrated by man and the great apes Advances in the Study of Behavior 9 131-158

Short RV (1981) Sexual selection in man and the great apes. In Reproductive Biology of the Great Apes pp 319-341 Ed. CE Graham. Academic Press, New York
Silk JB, Short J, Roberts J and Kusnitz J (1993) Gestation length in rhesus macaques (Macaca mulatta) International Journal of Primatology 14 95-104

Small MF (1988) Female primate sexual behavior and conception. Are there really sperm to spare? Current Anthropology 29 81-100

Smith DG (1994) Male dominance and reproductive success in a captive group of rhesus macaques (Macaca mulatta) Behaviour 129 225-242

Smith DG and Smith S (1988) Parental rank and reproductive success of natal rhesus males Animal Behaviour 36 554-562

Sokal RR and Rohlf FJ (1981) Biometry (2nd Edn) WH Freeman, San Francisco

Stern BR and Smith DG (1984) Sexual behavior and paternity in three captive groups of rhesus monkeys (Macaca mulatta) Animal Behaviour 32 23-32

Thompson DL Jr, Pickett BW, Squires EL and Amann RP (1979) Testicular measurements and reproductive characteristics in stallions Journal of Reproduction and Fertility Supplement 27 13-17

Trivers RL (1972) Parental investment and sexual selection. In Sexual Selection and the Descent of Man, 1871-1971 pp 136-179 Ed. B Campbell. Aldine, Chicago

Toelle VD and Robison OW (1985) Estimates of genetic correlations between testicular measurements and female reproductive traits in cattle Journal of Animal Science $6089-100$

Vandenbergh JG and Vessey S (1968) Seasonal breeding of free-ranging rhesus monkeys and related ecological factors Journal of Reproduction and Fertility $\mathbf{1 5}$ $71-79$

van Wagenen G and Catchpole HR (1956) Physical growth of the rhesus monkey (Macaca mulatta) American Journal of Physical Anthropology 14 $245-273$

Weinbauer GF and Nieschlag E (1990) The role of testosterone in spermatogenesis. In Testosterone: Action, Deficiency, Substitution pp 23-50 Eds E Nieschlag and HM Behre. Springer-Verlag, Berlin

Wilkinson L (1990) SYSTAT: The System for Statistics Systat Inc., Evanston

Wilson AP and Boelkins RC (1970) Evidence for seasonal variation in aggressive behaviour by Macaca mulatta Animal Behaviour 18 719-724

Wilson EO (1975) Sociobiology: The New Synthesis Belknap Press of Harvard University, Cambridge

Zar JH (1974) Biostatistical Analysis Prentice-Hall, Englewood Cliffs 